\title{
A NOVEL PROCEDURE MODEL FOR DEVELOPING INDIVIDUALIZED DIGITALIZATION STRATEGIES
}

\author{
P. Pfenning ${ }^{1, \bigotimes}$ and M. Eigner ${ }^{2}$ \\ ${ }^{1}$ Siemens Digital Industries Software, Germany, ${ }^{2}$ Technische Universität Kaiserslautern, Germany \\ $\bigotimes$ philipp.pfenning@siemens.com
}

\begin{abstract}
Many companies face a challenge while defining their individualized digitalization strategy. Therefore, the interrelation of corporate and digitalization strategy is addressed and a novel procedure model to assist companies in defining their strategy is introduced. Based on their corporate strategy, the introduced model allows companies to simply identify suitable business model patterns, digitization use cases and offers a possibility to asses the maturity level of their internal processes and evaluate the added value from an economic point of view.
\end{abstract}

Keywords: digital value chains, business models, design strategy, design process

\section{Introduction}

Digitalization is one of the most frequent discussed topics in industry. The importance of digitalization is undisputed; however, it is still unclear how companies can explicitly approach digital transformation and realize it in a structured way. In fact, digitalization is only the means and not the goal and should make organizations more efficient, productive and ultimately profitable. The aim of this paper is to highlight the necessity and diversity of companies' strategies and to show how manufacturing companies can develop an individualized digitalization strategy in order to profitably exploit the opportunities of digital transformation. The second section clarifies the need and goals for the development of digitalized smart products, services and processes. The subsequent section focuses on the strategy and the strategy process. In this context, in addition to the definitions, the levels of the strategy spectrum and the corporate strategy models will be addressed. This is followed by a section overviewing digitalization application perspectives and discussing relations between digitalization and corporate strategies. The research gap will be pointed out by overviewing existing models in literature. It is followed by presenting a procedure model for developing individualized digitalization strategies. The development of this study follows the CASE research cycle (clarification - analysis - synthesis - evaluation) according to Müller (2014) and is still ongoing. The following parts of this contribution provide insight into results of the clarification and analysis phase (see section 2 and 3) and the current state of the approach's synthesis in section 4 . The evaluation of the approach through more case studies appertains to future intends and will exemplarily addressed in the 4 section.

\section{Background}

Digitalization has become the innovation motor in a broad range of industries (Porter and Heppelmann, 2015) and with this technological shift the conventional nature of technical, economic 
and social processes has changed drastically (Bley et al., 2016). Two significant effects are reasoned for these circumstances. On the one hand side the rapid information transfer and processing capabilities of cybertronic systems and on the other hand the entrance of digital working tools and equipment in engineering and production processes (Anderl et al., 2012).

The customer's demand for innovative products and increasing global sourcing and manufacturing put pressure on companies and result in a fast development pace of products and accompanying services. Hence, current product innovation research is focused on designing smart products and services via the digitalization of products and associated digital services (Eigner et al., 2017; Dickopf et al., 2019) Possible impacts could be new products, new business processes, changes in revenue models, new sales and service forms, and changes in supply chain (Matt et al., 2015).

As a consequence, companies and their employees associate digitalization primarily as a "way out of the comfort zone", since almost everything revolves around innovation, speed and change (Hille et al., 2016). Therefore, it is not very surprisingly that 55 percent of medium-sized companies in Germany regard digital transformation as a central challenge according to a BITKOM study (Humpert, 2017). Even though companies consider digitalization as a challenge, they also envision an opportunity in potential benefits. These are diverse and include increases in sales or productivity, innovations in value creation, optimized processes, work system and competencies enhancement as well as novel forms of interactions with customers, among others (Tafvizi Zavareh et al., 2018). Against the backdrop that digitalization can reshape or replace entire business models (Downes and Nunes, 2014) every company needs to define a digitalization strategy (Hille et al., 2016). As there is currently a lack of supporting methods for evaluating digitalization measures and their potentials for companies strategies and business models, a demand for studies on direct and indirect effects of digitalization solutions exists (Wagner et al., 2017).

Regarding the large number of available technologies, selecting and implementing the best solution seems to be hardly possible without an appropriate assessment method. Therefore, this paper attends the purpose to introduce a procedure model to define individualized digitalization strategies for manufacturing companies.

\subsection{The strategy process}

There are many interpretations of the term strategy, wherefore a uniform definition does not exist. Generally, strategy is a plan to accomplish a desired future state, such as an achievement of a goal or finding a solution for a problem. Moreover, it implies a combination of measures by which the future state is to be achieved (Andrews, 1980). On a more economical point of view a strategy should ensure the long-term "survival of the company" (Schulte-Derne, 2005).

Defining a strategy can be expressed by the strategy development process. It consists of four development stages, which are shown in Figure 1 - Vision, Mission, Corporate goals and the intended strategy (Brecht, 2012). The first stage is the vision, which formulates a clear picture of the company's future (Sternad, 2015). The vision must be understood by all employees and they must also be able to identify themselves with it (Hungenberg, 2014). This makes the vision a "guiding idea directed towards the future" and predefines the direction in which a company should develop (Daum et al., 2016). The four characteristics - meaningful, motivating, guiding and integrating - must always be fulfilled (Müller-Stewens and Lechner, 2016).

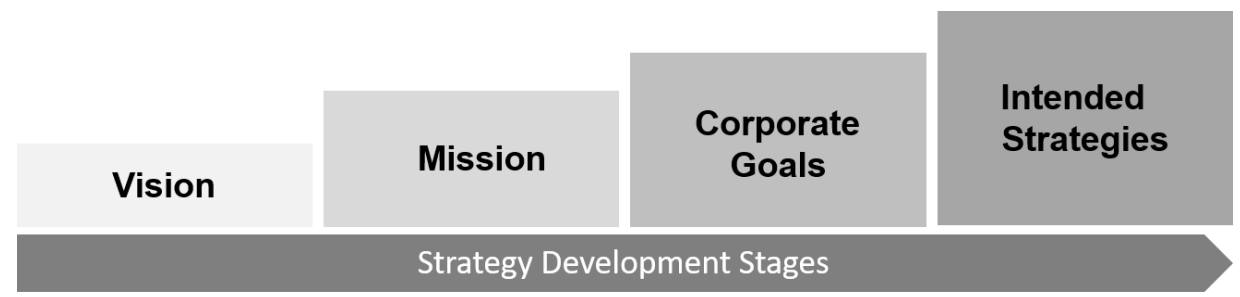

Figure 1. Stages of the strategy development process

Over time the vision needs to be more concretized, where the mission comes into play. The mission statement expresses the target the company should pursue and thus defines the objective statement of the company more precisely (Brecht, 2012). 
A mission shows a more short-term character than a vision. It must not relate to the future, but can also focus on a task in the present that is considered valuable and that justifies the existence of the company (Kranz and Rasche, 2007).

Vision and mission are the basis for the company's goals, the third stage of development (Brecht, 2012). In these, the contents of the vision and mission statements are concretized (Bates and Dillard, 1991).

In principle, a company has two types of goal orientation available - the shareholder approach and the stakeholder approach. The first emphases the interests of the shareholders. The focus is on economic goals, i.e. profit maximization. The stakeholder approach, on the other hand, focuses on the various interest groups and on generating the benefits of the company's economic performance for them (Hungenberg, 2014). In both approaches the goals should deal with "growth, profitability, technology, product offerings and markets to be served" (Fueglistaller et al., 2016).

With the guidance of the introduced stages - vision, mission and corporate goals - the fourth and last stage the intended strategy is obtained. Since strategies should be derived from the fundamental corporate goals (Macharzina and Wolf, 2012).

In order to support companies defining a corporate strategy several models have been proposed. One of the best-known models are Porter's generic competitive strategies. According to Porter a company should focus either on a price leadership, differentiation or niche strategy (Porter, 1997, 1998). This means a company should either focus on competitive prices, delivering high-end and leading-edge solutions or concentrate on a niche market. This model is often be considered as a basis for growth strategies of firms in general (Zimmerer and Scarborough, 1996; Hunger and Wheelen, 2000).

Another corporate strategy model comes from Treacy \& Wiersema with their value disciplines (Treacy and Wiersema, 1997). It extends porters generic strategy models and specifies a company's culture, organization, core processes, management system, as well as the IT infrastructure based on the selected strategy. As illustrated by Treacy \& Wiersema a company focuses on different core processes depending on their selected generic corporate strategy. For instance, a company following an Operational Excellence Strategy, aims to offer the most cost-effective product while concentrating on production and service processes. Other enterprises positioning themselves with a Product Leadership or Customer Intimacy strategy scrutinize different processes as engineering or sales related processes. As mentioned by Treacy \& Wiersema a company should primarily focus on one strategy otherwise a company would be stuck in the middle and less efficient (Treacy and Wiersema, 1993).

Another important factor in designing strategies is the competition situation within an industrial sector. Porter's Five Forces is a framework for analyzing a company's competitive environment. The number and power of a company's competitive rivals, potential new market entrants, suppliers, customers, and substitute products influence a company's profitability. Porter's five forces model is based on the approach of industrial economics. It assumes that the attractiveness of an industry for a company operating in it, is determined by the market structure, since this influences the behavior of market participants. From the development of the competitive situation in an industry, it can be deduced whether it is attractive for the company, i.e. whether it enables long-term profitable development. Digitalization influences (shifts) the forces of industry structure, especially with regard to the "threat of new suppliers" and "substitution products" (Loebbecke, 2006). New technologies enable previously unknown players to successfully gain a foothold in traditional industries. More and more digitalized products and business models (e. g. platforms, highly individualized and adoptive products, product-service systems, availability-oriented business models), are replacing the previously analogue product services and business models (Goebel, 2018).

A business model is closely linked to a company's corporate strategy and outlines the fundamental principle of how a company generates, facilitates and capture value (Osterwalder and Pigneur, 2010). Furthermore, it defines who are the customers, what should be sold, how the product or service is produced and how revenue is generated (Gassmann et al., 2017). Research has shown that successful companies apply similar business models and therefore more than 50 business model patterns have been defined and utilized in procedure models to innovate existing business models. (Gassmann et al., 2017; Gausemeier et al., 2017). 
To summarize it, the discussed approaches relay on structure analysis of branches and identification of companies positioning ambitions to define their products or services for specific or broad markets.

But through which mechanism does digitalization affect a company's strategy and how the necessitation of adopting or creating new strategies could be vindicated? To address these issues the interdependence of technologies (including digitalization) and strategies will be addressed in the next section.

\subsection{Interrelation of corporate strategy, digitalization strategy and innovative technologies}

In literature various definitions for a digitalization strategy exist (Schallmo and Lohse, 2020; Rauser, 2016; Bharadwaj et al., 2013; Matt et al., 2015). Most of them address similar aspects which are summarized as follows. A digitalization strategy constitutes a holistic intention of a company to streamline all activities regarding the digital transformation process to generate competitive advantages through new technologies and methods to optimize products, processes and business models. In fact, digitalization influences the overall strategy of the company and goes far beyond the mere technology trend.

As depicted in Figure 2, a digitalization strategy follows the overall corporate strategy. To achieve the goals of a corporate strategy every department participating in the value chain like sales, product management, engineering or manufacturing must define their own operational strategy more precisely.

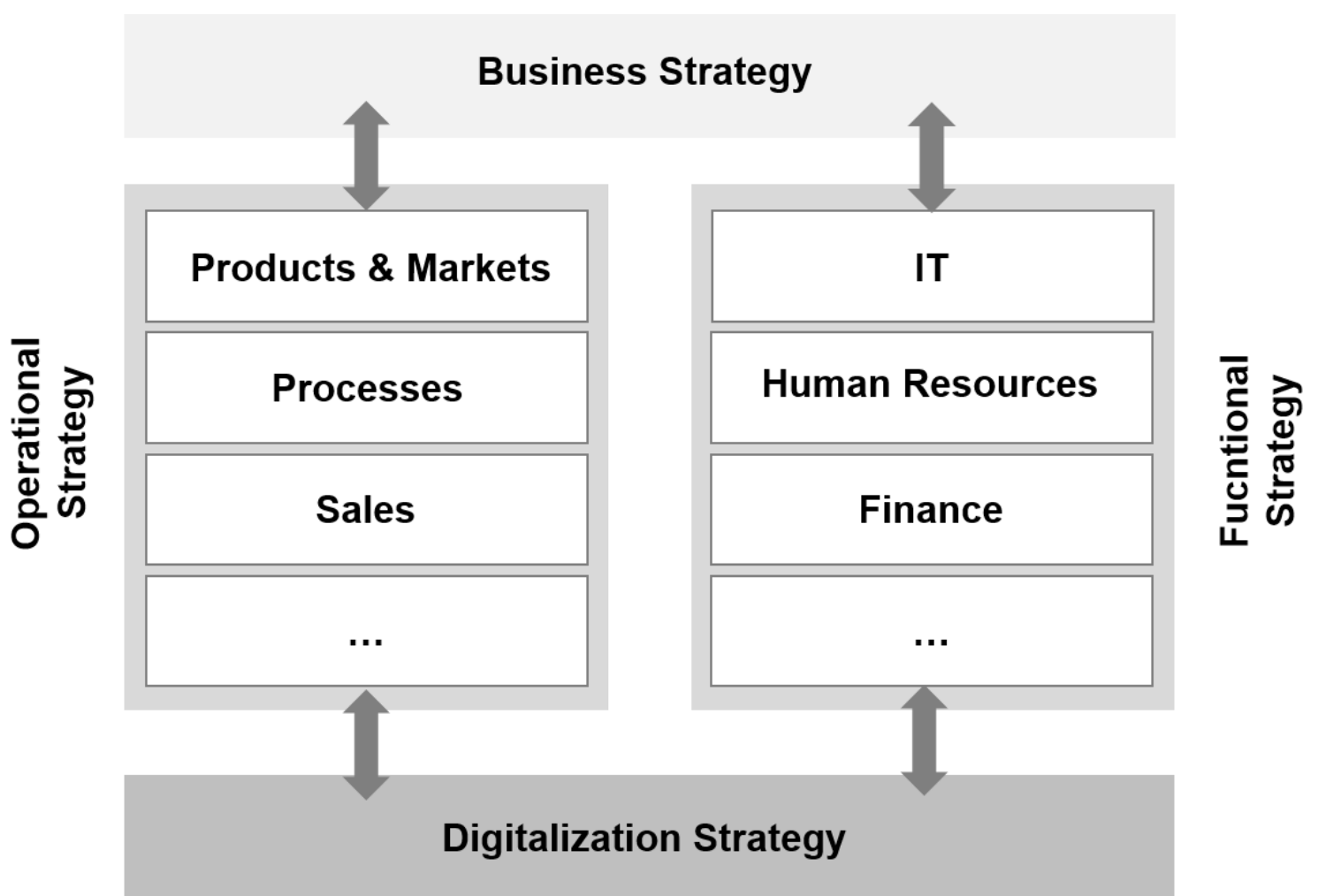

Figure 2. Digitalization strategy contextualized (based on Matt et al., 2015)

On the other hand, cross sectional departments such as IT, human resources or finance must define their functional strategy under consideration of the overall corporate strategy. Therefore, it can be stated that defining a digitalization strategy affects every department not only in its IT infrastructure but also in its processes as well as in the overarching organizational structure.

A digitalization strategy sets digital objectives for a defined planning period and formulates measures for medium to long-term implementation (Bitkom Research and Tata Consultancy Services, 2018). Some core strategical potentials and field of actions of digitalization are illustrated in Figure 3. Typical areas of digitalization span from customer experience scenario allowing companies to address customer needs, over innovative new digital-enriched products and services, new internal digitalization projects to boost a company's productivity and changing mindsets and skills within organizational culture. 


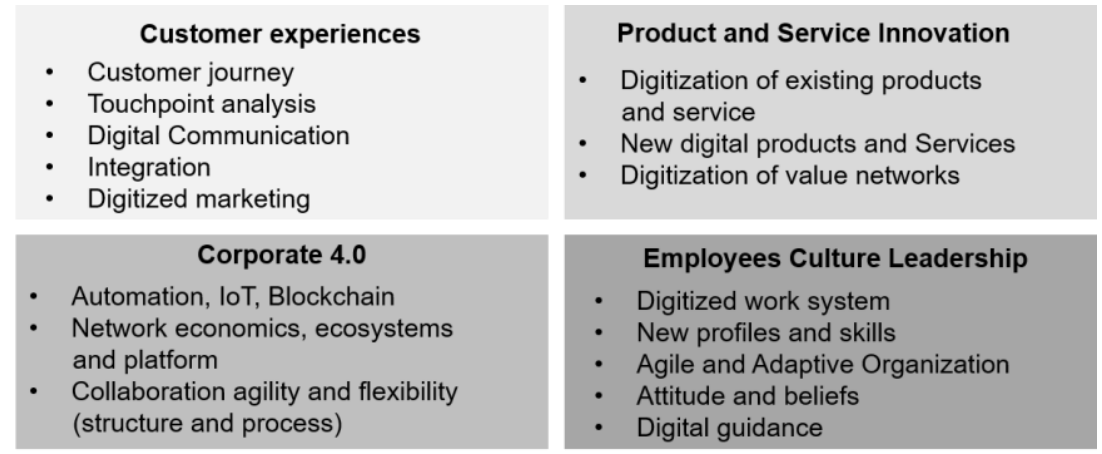

Figure 3. Field of actions in the context of digitalization (based on Kreutzer and Land, 2015)

Technological innovations lead to the necessity to continuously adapt the corporate strategy, since on the one hand corporate strategy determines the use of technologies and innovations in the company. On the other hand, impacts of technical innovations can lead to changed environmental conditions for companies. For instance, the entry of new competitors or new digitalized products transforms the industry structure and makes it necessary to adapt corporate strategy.

According to Loebbecke three possible cases for the relationship between corporate strategy and technologies can be grasped (Loebbecke, 2006)

- Decisions on the nature and extent of the use of certain technologies are derived from the overarching corporate strategy. Technology is used to implement a strategy (Porter, 1998).

- Digital technologies influence competitive conditions, both through changes in market conditions and through fundamental changes in processes (Galliers, 1993).

- Interdependent relationship between strategy development and technology deployment. Decisions must be made simultaneously, since corporate and technology strategies influence each other (Becker, 1999).

As described above, both digitalization strategy and corporate strategy define long-term goals for the company and are therefore closely linked to each other. In order to avoid conflicts, the objectives of the digitalization strategy must therefore be consistent with the objectives of the corporate strategy.

\section{Comparison of related work}

Before presenting the procedure model for the development of an individualized digitalization, four existing approaches for this purpose will shortly be covered and evaluated against various criteria namely the consideration of corporate strategy, business models, digitalization use cases, internal processes, detailed maturity models and the possibility to perform an economic evaluation.

The Digital Capability Framework aims to lead a company into a digital enterprise. For this purpose, it consists of four building blocks (Digital capabilities, digital capability maturity model, digital use cases and digital transformation roadmap) (Uhl et al., 2016). This indicates that the model addresses several of the underlying criteria. However, it does not offer any reference to corporate strategy, business models nor to any economic evaluation capabilities.

The Roadmap approach by Schallmo and Rusnjak focuses on the digital transformation of business models (Schallmo and Rusnjak, 2017). Thereby, a five-phase procedure model has been defined. It allows to analyze the current status of the business model, to identify and to detail possible future opportunities with new products and services and the deployment of the intended ideas. It scrutinizes a company's business model and does neither fully meet the requirements to digitalize internal processes to increase productivity nor allows to evaluate the benefits from an economic point of view. Likewise, to the previous approach the Industry 4.0 business model by Kaufmann focuses on the definition of new business models via maturity models, business model patterns, design thinking techniques and economic evaluation methods (Kaufmann, 2015). However, projects to raise the efficiency of internal processes are not explicitly addressed.

The last approach by the German Engineering Federation (VDMA) emphasizes the value of digitalization projects. Therefore, a procedure model has been determined allowing companies to 
identify typical digitalization use cases, evaluate their current maturity level and define an intended maturity status (Illner et al., 2018). The application of key performance indicators based on VDMA member data through a web-based tool allows companies to identify a rough estimation of possible costs and benefits. This procedure model should only indicate potential use cases and corresponding financial aspects. It does not address any relations to corporate strategy or business models. The evaluation for the named models regarding the introduced criteria can be obtained in Figure 4.

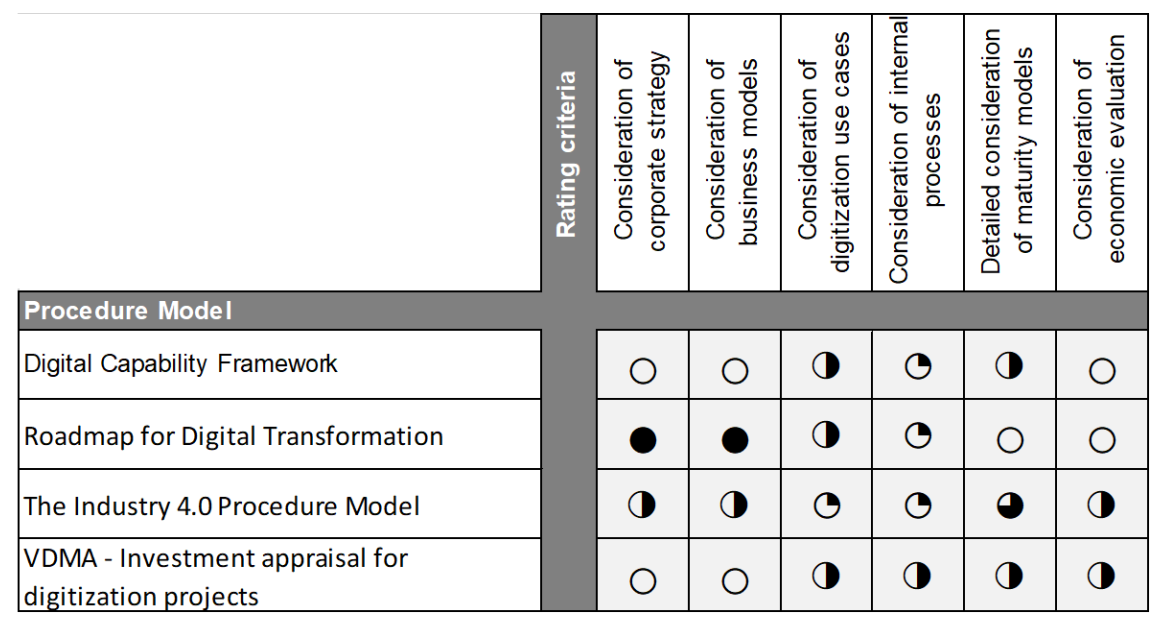

Figure 4. Evaluation of existing procedure models

In summary it can be stated, that most existent procedure models focus on business model transformation and do not address internal processes like product development in detail. Therefore, a procedure model has been developed meeting all predefined requirements in order to holistically define a digitalization strategy. This will be introduced within the next section.

\section{The procedure model for developing individualized digitalization strategies}

To support companies in defining their specific individualized digitalization strategy a comprehensive procedure model has been established. The Totally Integrated Potential Analysis Framework (TIPAF) provides guidance throughout the definition process. The model is composed of several abstraction levels which are introduced and illustrated in Figure 5.

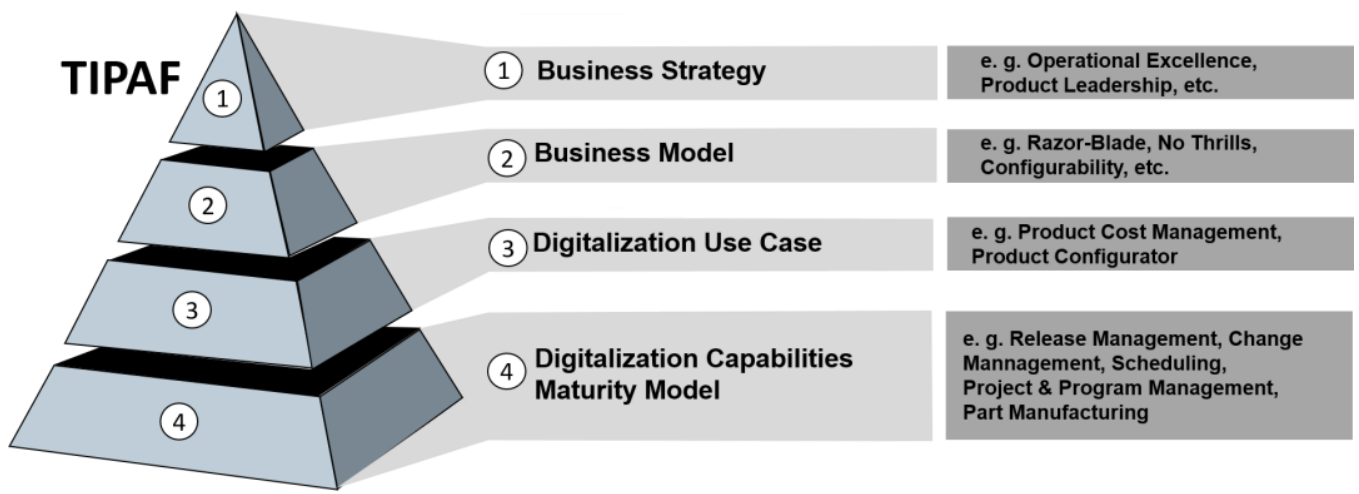

Figure 5. Levels of the TIPAF model

The top and most abstract levels are the corporate strategy and its corresponding business models. The corporate strategy is based on the work of Treacy \& Wiersema, as discussed in section 3, with their value disciplines (Treacy and Wiersema, 1997). Depending on a company's decision to follow a Customer Intimacy, Product Leadership or Operational Excellence strategy, suitable business model patterns, which supports the chosen corporate strategy differs. By choosing a certain strategy the TIPAF model helps to identify relevant business model patterns, based on the identified patterns of 
Gassmann et al. (Gassmann et al., 2017) as described in section 4. For this purpose, an associative relationship between corporate strategy and business model pattern is deposited in the model - as illustrated in the matrix in Figure 6. For further definitions of individual business model patterns corresponding literature can be consulted (Gassmann et al., 2017).

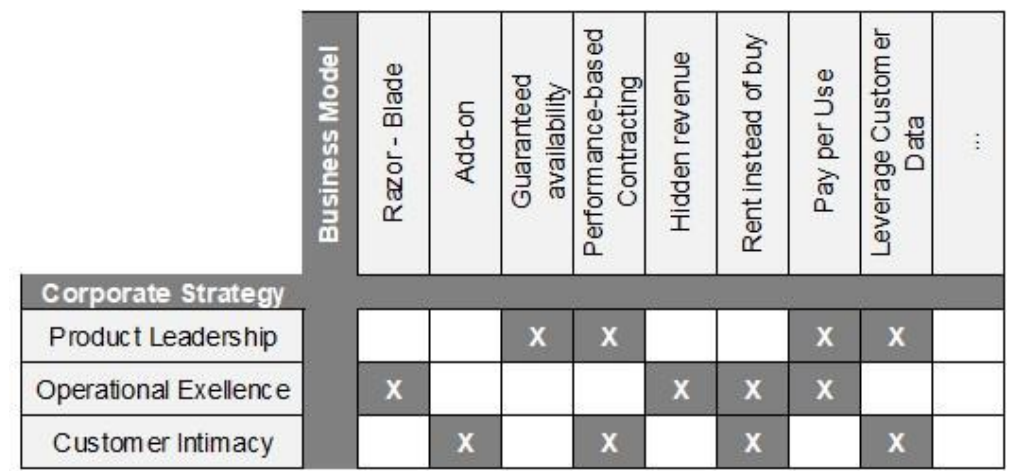

Figure 6. Relationship-matrix between corporate strategy \& business model pattern

For a company that follows an operational excellence strategy it might be useful to apply a razor blade business model pattern. This means that a company offers its initial product either for free or at least for manufacturing costs. However, side-products, which are needed to utilize the product, are used to generate revenue as they are offered for a more expensive price. An example for this business model could be a company offering capsule-based coffee machines where the machine is offered for an affordable price and the revenue is mostly generated by the sales of capsules.

The digitalization use cases constitute the third level of the TIPAF pyramid and describe common application scenarios in the context of digitalization. Depending on the chosen business model several digitalization use cases are suitable to support the business model. Again, the principle of associative relationships can be applied between business model patterns and digitalization use cases.

For instance, the introduction of the use case product cost calculation allows companies to systematically define the costs under consideration of material, manufacturing processes and logistics costs. In case of the preliminary introduced coffee machine this approach allows to determine the retail prices and therefore supports the razor-blade business model. This level of the pyramid often refers to new technologies and enterprise IT systems. This emerging relationship is deposited in the procedure model allowing companies to identify useful technologies while discussing a use case. Regarding the coffee machine example, professional product cost calculation systems might be of interest for companies focusing on this use case.

In order to assess a company's current maturity level their capabilities can be analyzed via a maturity model. This underlying maturity model has been developed constitutes the bottom part of the TIPAF methodology by covering several aspects of a company's digitalization. It begins in the planning phase of a product, spanning over design and production phase, into operational and service phase. Within this model a company can define its current and targeted status on a five-tier scale with predefined criteria and compare itself to an industry benchmark. So far, the benchmark data contains almost two hundred companies and overall a set of fifty digital capabilities which are linked to corresponding use cases. Coming back to the previously introduced digitalization use case product cost calculation of the coffee machine manufacturer. The digital capabilities release management, cost management, change management, and manufacturing process management contribute to fulfil the use case.

After the evaluation of the current status, it is possible to define a targeted status in the maturity model, which allows in turn to define required work packages to get to this level. This work packages can imply process adjustments, new technologies or IT systems as well as organizational changes.

Moreover, financial aspects are also of significant importance to evaluate the implementation of a digitalization strategy. Once use cases have been defined, it is possible to conduct an economic analysis via the TIPAF methodology. Therefore, typical benefits are assigned to corresponding use cases by using a best practice approach. Thereby, three kinds of benefits are distinguished - Timebased benefits, Cost-based benefits and qualitative improvements. 
Whereas time-based benefits can be transformed via an hourly rate of the underlying resource (machine or worker) into a money-equivalent and cost savings are already monetized, qualitative improvements cannot be expressed in a monetary way. An example for a soft fact is the improvement of data quality which helps a company only indirectly to be more profitable.

As depicted in Figure 7, the use case product cost calculation features several benefits. For instance, the employee performing the cost calculation needs less time for gathering information, as relevant data is already available. To concretize and verify the benefits subject matter experts should be consulted.

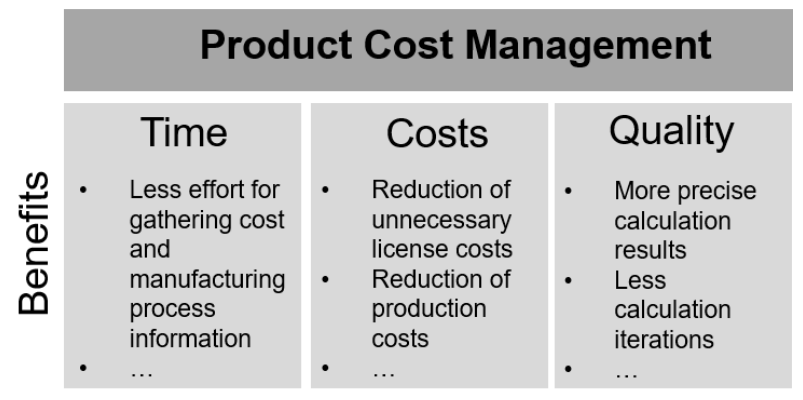

Figure 7. Benefits of a digitalization use case - Product Cost Management

Additional to the benefits of a use case the costs need to be considered. They are classified as license cost, external services (e. g. implementation services), software maintenance, additional hardware as well as internal efforts such as the participation in workshops or trainings.

Once use cases together with projects boundary conditions are defined, it is possible to compute financial key performance indicators (KPI) such as Net Present Value (NPV), Internal Rate of Return (IRR) and payback period by using a discounted cashflow model. These KPIs support a decision maker to compare a project to others and therefore provide guidance whether a project is profitable from an economic point of view or not.

The TIPAF procedure model itself can be applied in different ways. Based upon whether a company is using a top-down-approach to determine a completely new digitalization strategy or only wants to enhance the digitalization strategy in place via a bottom-up-approach. The second variant allows in turn to evaluate new technologies and to reshape business models due to the interrelation of corporate strategy and technology as indicated in section 2.2. The process of the procedure model is illustrated in Figure 8.

\begin{tabular}{|c|c|c|c|c|c|}
\hline \multicolumn{6}{|c|}{ Defining a new digitalization strategy - Top-Down approach } \\
\hline $\begin{array}{l}\text { Select corporate } \\
\text { strategy }\end{array}$ & $\begin{array}{c}\text { Select } \\
\text { corresponding } \\
\text { business model } \\
\text { pattern }\end{array}$ & $\begin{array}{c}\text { Select } \\
\text { corresponding } \\
\text { Use Case }\end{array}$ & $\begin{array}{l}\text { Perform } \\
\text { Maturity } \\
\text { Analysis }\end{array}$ & $\begin{array}{l}\text { Define intended } \\
\text { state within } \\
\text { Maturity Model }\end{array}$ & $\begin{array}{l}\text { Perform } \\
\text { economic } \\
\text { evaluation of } \\
\text { Use Case }\end{array}$ \\
\hline & & \multicolumn{4}{|c|}{ Enhancing existing digitalization strategy - Bottom-Up approach } \\
\hline
\end{tabular}

Figure 8. TIPAF - Procedure Model Process

In a first step, a corporate strategy as introduced in section 2.1 must be selected. Depending upon which strategy has been selected, suitable business model patterns are proposed which are then discussed and explored. After one or a combination of multiple business model pattern has been picked, the model indicates relevant digitalization use cases, which outline separate digitalization projects. Again, one or multiple use cases should be considered for the next phase - the maturity model phase. This phase allows a company to assess its capabilities to fulfil the selected use cases. After analyzing the current status and defining the intended maturity level, a company can derive required technologies and working packages to implement the use case. As financial aspects also need to be considered while defining a digitalization strategy, the model offers the possibility to perform an economic evaluation of the use case.

The introduced theoretical TIPAF Model has already been implemented in a software (application) prototype based on a low-code platform. First tests with the interactive application were auspicious 
and resulted in first digitalization strategies. Therefore, it can be stated that this procedure model allows to define a comprehensive digitalization strategy addressing corporate strategy, business models, digitalization use cases and new required technologies.

\section{Summary and outlook}

This research paper introduced an excerpt of corporate strategy models and showed the necessity to define a digitalization strategy. It is shown how technological innovations lead to the necessity to continuously adapt the corporate strategy. Both, corporate as well as digitalization strategy interrelate and so far, no holistic procedure models to define related digital business models and digitalization processes are available. The TIPAF Model has been introduced, which functions as guideline to identify various building blocks and technologies for customized digitalization strategies. Therefore, the TIPAF levels of corporate strategy, business models, digitalization use cases and digital capabilities, as well as the process to utilize the TIPAF has been introduced. Based on an example - a capsule-based coffee machine - the interrelations of the different level have been demonstrated. Moreover, the procedure model allows to illustrate the gained value through digitalization via an economic analysis.

Future research topics could be the statistical analysis of maturity data of the database in order to identify possible correlations or patterns. Furthermore, the practical application as part of a case study as well as the extension of digitalization use case could also be of interest.

\section{References}

Anderl, R. et al. (2012), Smart Engineering: Interdisziplinäre Produktentstehung, acatech DISKUSSION, April 2012, Springer, Berlin, Heidelberg.

Andrews, K.R. (1980), The concept of corporate strategy. Homewood, IL: Irwin.

Bates, D.L. and Dillard, J.E. (1991), "Desired future position-a practical tool for planning", Long Range Planning, Vol. 24 No. 3, pp. 90-99.

Becker, W.E. (1999), "Carl Shapiro and Hal R. Varian. Information Rules: A Strategic Guide to the Network Economy. Boston, Massachusetts: Harvard Business School Press, 1999. x + 352 pp", The Journal of Economic Education, Vol. 30 No. 2, pp. 189-190.

Bharadwaj, A. et al. (2013), "Digital business strategy: toward a next generation of insights", MIS quarterly, pp. 471-482.

Bitkom Research and Tata Consultancy Services (2018). Unterwegs zu digitalen Welten: Deutschland startet in die technologische Zukunft, available at: www.studie-digitalisierung.de.

Bley, K., Leyh, C. and Schaffer, T. (2016), "Digitization of German Enterprises in the Production Sector - Do they know how " digitized " they are?", Surfing the IT innovation wave: 22nd Americas Conference on Information Systems (AMCIS 2016), San Diego, California, USA, 11-14 August 2016, Curran Associates Inc., Red Hook, NY, pp. 736-746.

Brecht, U. (2012). BWL für Führungskräfte: Was Entscheider im Unternehmen wissen müssen, 2., überarb. und erw. Aufl. 2013, Springer, Wiesbaden.

Daum, A., Petzold, J. and Pletke, M. (2016), BWL für Juristen: Eine praxisnahe Einführung in die betriebswirtschaftlichen Grundlagen, 3. Auflage, Springer Gabler, Wiesbaden.

Dickopf, T. et al. (2019), "A Holistic System Lifecycle Engineering Approach - Closing the Loop between System Architecture and Digital Twins", Procedia CIRP, Vol. 84, pp. 538-544.

Downes, L. and Nunes, P. (2014), Big bang disruption: Strategy in the age of devastating innovation.

Eigner, M., Koch, W. and Muggeo, C. (2017), Modellbasierter Entwicklungsprozess cybertronischer Systeme: Der PLM-unterstützte Referenzentwicklungsprozess für Produkte und Produktionssysteme, Springer Vieweg, Berlin.

Fueglistaller, U. et al. (2016), Entrepreneurship: Modelle - Umsetzung - Perspektiven mit Fallbeispielen aus Deutschland, Österreich und der Schweiz, 4. Auflage, Springer Gabler, Wiesbaden.

Galliers, R.D. (1993), "Towards a flexible information architecture: integrating business strategies, information systems strategies and business process redesign", Information Systems Journal, Vol. 3 No. 3, pp. 199-213.

Gassmann, O., Frankenberger, K. and Csik, M. (2017). Geschäftsmodelle entwickeln, Hanser Fachbuchverlag.

Gausemeier, J. et al. (2017), Mit Industrie 4.0 zum Unternehmenserfolg - Integrative Planung von Geschäftsmodellen und Wertschöpfungssystemen, Heinz Nixdorf Institut.

Goebel, J.C. (2018), Unternehmerisches Denken und Handeln: Einführung und digitale Transformation, TU Kaiserslautern. 
Hille, M., Janata, S. and Michel, J. (2016). Leitfaden Digitalisierung: Strategien, Technologien und Ökosysteme, available at: https://www.qsc.de/assets/documents/rlch2015/pec/Leitfaden_Digitalisierung_QSC_AG.pdf.

Humpert, M. (2017). In 10 Schritten digital: Ein Praxisleitfaden für Mittelständer, available at: https://www. bitkom.org/sites/default/files/file/import/170601-In-10-Schritten-digital-Praxisleitfaden.pdf.

Hungenberg, H. (2014), Strategisches Management in Unternehmen: Ziele - Prozesse - Verfahren, 8., aktualisierte Aufl., Springer Gabler, Wiesbaden.

Hunger, J.D. and Wheelen, T.L. (2000), Strategic management, 7. ed., Prentice-Hall, Upper Saddle River, NJ.

Illner, B. et al. (2018). Leitfaden Investitionsrechnung für Digitalisierungsprojekte und Industrie 4.0 Vorhaben, Mühlheim am Main.

Kaufmann, T. (2015), Geschäftsmodelle in Industrie 4.0 und dem Internet der Dinge: Der Weg vom Anspruch in die Wirklichkeit, essentials, Springer Vieweg, Wiesbaden.

Kranz, M. and Rasche, C. (2007), Management von Strategieprozessen: Von der Strategischen Planung zur integrierten Strategieentwicklung, 1. Aufl., DUV Deutscher Universitäts-Verlag, s.l.

Kreutzer, R.T. and Land, K.-H. (2015), Digital Darwinism: Branding and Business Models in Jeopardy.

Loebbecke, C. (2006), "Digitalisierung - Technologien und Digitalisierung — Technologien und Unternehmensstrategien", In: Scholz, C. (Ed.), Handbuch Medienmanagement: Mit 46 Tabellen, SpringerVerlag Berlin Heidelberg, Berlin, Heidelberg.

Macharzina, K. and Wolf, J. (2012), Unternehmensführung: Das internationale Managementwissen Konzepte Methoden - Praxis, Lehrbuch, 8, vollständig überarbeitete und erweiterte Auflage, Springer Gabler, Wiesbaden.

Matt, C., Hess, T. and Benlian, A. (2015), "Digital Transformation Strategies", Business \& Information Systems Engineering, Vol. 57 No. 5, pp. 339-343.

Matzler, K. et al. (2013), "Business model innovation: coffee triumphs for Nespresso", Journal of Business Strategy, Vol. 34 No. 2, pp. 30-37.

Mintzberg, H. (1978), "Patterns in Strategy Formation”, Management Science, Vol. 24 No. 9, pp. 934-948.

Müller-Stewens, G. and Lechner, C. (2016), Strategisches Management: Wie strategische Initiativen zum Wandel führen der Strategic Management Navigator, 5, überarbeitete Auflage, Schäffer-Poeschel Verlag, Stuttgart.

Osterwalder, A. and Pigneur, Y. (2010), Business model generation: a handbook for visionaries, game changers, and challengers, John Wiley \& Sons.

Porter, M.E. (1997), “Competitive strategy”, Measuring Business Excellence, Vol. 1 No. 2, pp. 12-17.

Porter, M.E. (1998), Competitive strategy: Techniques for analyzing industries and competitors; with a new introduction, Free Press, New York, NY.

Porter, M.E. and Heppelmann, J.E. (2015), "How smart, connected products are transforming companies", Harvard business review HBR, Vol. 93 No. 10, pp. 96-114.

Rauser, A. (2016), Digital strategy: A guide to digital business transformation, CreateSpace Independent Publishing Platform.

Schallmo, D. and Lohse, J. (2020), "Digitalstrategie: Grundlagen, bestehende Ansätze und Vorgehensmodell", In: Doleski, O.D. (Ed.), Realisierung Utility 4.0 Band 1, Vol. 37, Springer Fachmedien Wiesbaden, Wiesbaden, pp. 79-95.

Schallmo, D. and Rusnjak, A. (2017), "Roadmap zur Digitalen Transformation von Geschäftsmodellen”, In: Schallmo, D., Rusnjak, A., Anzengruber, J., Werani, T. and Jünger, M. (Eds.), Digitale Transformation von Geschäftsmodellen, Vol. 1, Springer Fachmedien Wiesbaden, Wiesbaden, pp. 1-31.

Schulte-Derne, M. (2005), Transformation follows strategy: Transformation und Strategieentwicklung von Innen, Springer, Wien.

Sternad, D. (2015), Strategieentwicklung kompakt: Eine praxisorientierte Einführung, essentials, Springer Gabler, Wiesbaden.

Tafvizi Zavareh, M. et al. (2018). A Study on the socio-technical aspects of digitization technologies for future integrated engineering work systems.

Treacy, M. and Wiersema, F. (1993), "Customer intimacy and other value disciplines", Harvard business review, Vol. 71 No. 1, pp. 84-93.

Treacy, M. and Wiersema, F.D. (1997), The discipline of market leaders: Choose your customers, narrow your focus, dominate your market, [Expanded edition], Addison-Wesley Pub. Co, Reading, Mass.

Uhl, A. et al. (2016), "Digital Capability Framework: A Toolset to Become a Digital Enterprise", In: Uhl, A. and Gollenia, L.A. (Eds.), Digital enterprise transformation: A business-driven approach to leveraging Innovative IT, Routledge, London, New York, pp. 27-60.

Wagner, T., Herrmann, C. and Thiede, S. (2017), "Industry 4.0 Impacts on Lean Production Systems", Procedia CIRP, Vol. 63, pp. 125-131.

Zimmerer, T.W. and Scarborough, N.M. (1996), Entrepreneurship and new venture formation, Prentice Hall, Upper Saddle River, N.J. 